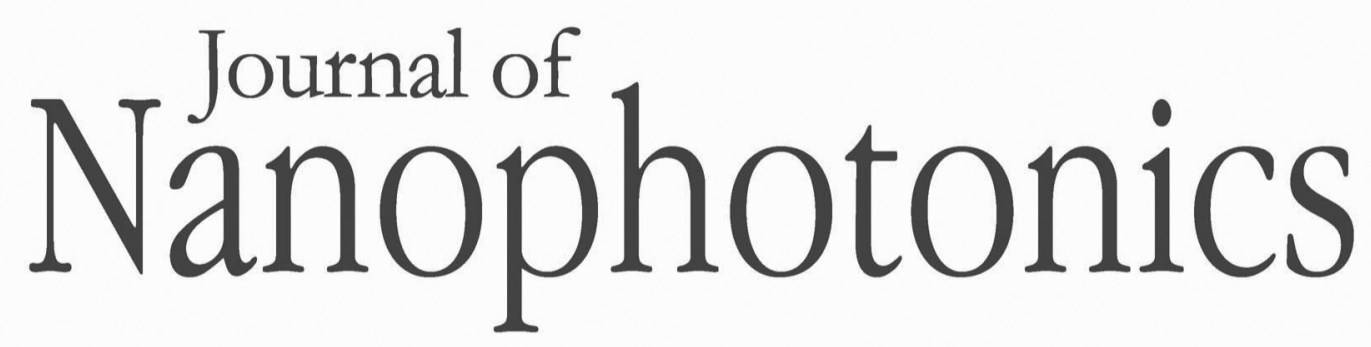

SPIEDigitalLibrary.org/jnp

\title{
Special Section Guest Editorial: Selected Papers from the 4th Mediterranean Conference on Nanophotonics
}

Zeev Zalevsky

Ekmel Ozbay

Ibrahim Abdulhalim 


\title{
Special Section Guest Editorial: Selected Papers from the 4th Mediterranean Conference on Nanophotonics
}

\author{
Zeev Zalevsky, ${ }^{a}$ Ekmel Ozbay, ${ }^{\mathrm{b}}$ and Ibrahim Abdulhalim ${ }^{\mathrm{c}}$ \\ ${ }^{a}$ Bar-Ilan University, Faculty of Engineering, Ramat-Gan 52900, Israel \\ zalevsz@biu.ac.il \\ ${ }^{\mathrm{b}}$ Bilkent University, Nanotechnology Research Center (NANOTAM), Bilkent, Ankara 06800, \\ Turkey \\ ozbay@bilkent.edu.tr \\ ${ }^{\mathrm{c} B e n-G u r i o n}$ University, Electro-optics Engineering, Beer-Sheva 84105, Israel \\ abdulhlm@bgu.ac.il
}

On 24-25 October 2011 the MediNano-4 meeting was held in the historical city of Rome, Italy, following the successful gatherings of MediNano-1, 2, and 3, which were organized in Istanbul, Turkey, in 2008, Athens, Greece, in 2009, and Belgrade, Serbia, in 2010. As before, the meeting included several tens of participants from many countries (mostly, but not exclusively, from the Mediterranean), who presented the highlights of their recent achievements in the field of nanophotonics.

This special section presents several papers that were submitted by researchers following their participation in the MediNano-4 event. This year the papers presented in this special section can be divided into several topics, including metamaterial configuration designs; nanophotonic and plasmonic devices, such as photonic logic gates, Viterbi decoders, and plasmonic couplers; nanofabrications, such as gold nanostructure arrays and biosensors; and optical characterization of various nanophotonic structures, such as multilayer thermochromic $\mathrm{VO}_{2}$-based structures, surface-enhanced Raman scattering, absorption enhancement in InGaN-based photonic crystals, and spherical quantum dots and wells.

The MediNano-5 meeting will take place in Barcelona, Catalonia, Spain, at the Institute of Photonic Sciences (ICFO), on 5-6 November 2012 and will follow the tradition established by the previous MediNano meetings. 